\title{
Student-Centered Group-Based Learning System
}

\author{
Adeyemo, O.A. ${ }^{1}$ \\ Department of Mathematical and Physical Science \\ AfeBabalola University, Ado-Ekiti \\ Ekiti, Nigeria \\ adeyemo@abuad.edu.ng \\ Abiola O.B ${ }^{3}$ \\ Department of Mathematical and Physical Science \\ AfeBabalola University, Ado-Ekiti \\ Ekiti, Nigeria \\ abiolaob@abuad.edu.ng \\ Olatunji K.A ${ }^{5}$
Okesola Ajibola ${ }^{2}$
Department of Mathematical and Physical Science
Afe Babalola University, Ado-Ekiti
Ekiti, Nigeria
okesolaajibola@gmail.com
Oguntimilehin A ${ }^{4}$
Department of Mathematical and Physical Science
Afe Babalola University, Ado-Ekiti
Ekiti, Nigeria
abiodunoguns@abuad.edu.ng \\ Department of Mathematical and Physical Science \\ AfeBabalola University, Ado-Ekiti \\ Ekiti, Nigeria \\ olatunjika@abuad.edu.ng
}

Received Date : October 12, 2021 Accepted Date : November 13, 2021 Published Date : December 06, 2021

\begin{abstract}
This study developed a student-centered group-based learning system. The system requirements were gathered from relevant literature on pedagogy and WebRTC. The study identified social loafing as a major drawback of most student-centered learning groups. The system was designed using block, architectural pattern, flow-chart, use-case, sequence, class and architectural-context diagrams and the system's application logic was implemented using ASP.NET C\#; HTML, JAVASCRIPT and BOOTSTRAP for the front-end and SQL for the database, HangFire and SignalR for the reminder and texting system. SendGrid API for reminders and OpenVidu Media server for video and audio-calling. The system has been tested and proven to be effective in providing different forms of communication and structure to group-learning that reduces social loafing, and can be recommended for tertiary institutions who want to promote a better student-student relationship for improved learning.
\end{abstract}

Key words :Pedagogy, Study group, WebRTC, Group-learning

\section{INTRODUCTION}

A lot of training time is devoted to helping teachers plan proper interactions between their students and the study materials (i.e., textbooks, curriculum programs) and some time is spent training on how teachers should interact with their students, however the way students should interact with other students is relatively ignored. How teacher's structure studentto-student interaction has a lot to say about how students feel about each other, how well they learn, how they feel about school and the teacher, and how much self-esteem they have [1].

According to [2], There are three basic ways students can interact with each other as they learn; They can compete to see who is "best", they can work individualistically without paying attention to other students, or they can work cooperatively with great interest in each other's learning as well as their own Group-based learning creates an environment in which students can practice, gain, and improve soft skills such as leadership, communication, social, and conflict resolution skills. However, simply placing students in groups and creating group-based assessment tasks will not necessarily result in students developing and practicing these skills.[3]. Instead, problems such as social loafing may arise if groupbased learning is not properly implemented

Social loafing is viewed in this study as a behavior pattern wherein an individual working in a group setting fails to contribute his or her fair share to a group effort as perceived by group members, but merit from other members' work due to a common grading system for the group [4]. Group-based work such as collaborative, project-based or cooperative learning should be performed while considering the opinion of the students to avoid forcing students who already learn significantly well individually and are more comfortable in that manner, and also to avoid forcing introverted or socially anxious students into a form of interaction tasking on their mental health and their personalities which may in turn affect their ability to assimilate and work effectively.

Literature has it that even just one social loafer can affect the performance of the whole group.[4]. It is therefore important 
to structure online group-learning environments to limit social loafing, hence, this study.

In the proposed system for student-centered group-based learning, our focus is on the involvement of flexible studentformed group creation, Incorporation of various forms of online communication to facilitate communication among students. The system will have a web-based implementation. However, the proposed system will not cover pre-determined grouping of students according to any category (i.e., gender, grade level, etc.), evaluation or review of group's academic progression as the system shall be implementing already researched concepts and not re-establishing them.

\section{LITERATURE REVIEW}

Student-centered pedagogy is an approach where students influence the outline, activities, pace and content of the learning [5]. It promotes soft-skills in students such as collaboration and communication. Communication is a dynamic, constantly changing process by which we understand and then try to be understood [6]. With the rise in technology, several different kinds of communication have arisen and one of the most influential in collaboration is real-time communication.

\section{A. Theoretical Concepts 1) Pedagogy}

Pedagogy is an independent social anthroposophical science. It is an organized science about humans that represents a system of research about education processes as well as main agents of the processes, conditions, results, and factors that determine the education. Pedagogy is the study of the diversity and versatility of education [7]. Student-centered pedagogy does not have one universal definition, in spite of the lack of a central definition, there is a principle that has been agreed upon by all proponents and researchers of the Student-centered learning approach and this principle finds its basis in the philosophy that the student or the learner is at the heart of the learning process [8]. Several different instructors have created their own approaches and named them accordingly, thus creating a broad spectrum of student-centered pedagogy among which includes: Active Learning, Collaborative Learning, Inquiry-based Learning, Cooperative Learning, Problem-based Learning, Team-based Learning, Peer Instruction, Just-in-Time Teaching, Small Group Learning, Project-based Learning, etc.

\section{2) WebRTC (Web Real-Time Communication)}

WebRTC is a free open-source project that provides real-time communication (RTC) functionalities for audio (voice call), video chat, and data (file sharing) through browser-to-browser communication. It allows browsers to communicate directly with each other in a peer-to-peer manner, which is different from conventional browser-to-web server communication [9]. WebRTC Provides several functionalities and benefits in regards to communication, however it was designed for peerto-peer connections meaning that with simple WebRTC, it is very easy to design and implement a one-to-one video call, audio call or data channel but to design and implement one for a group of several different users would require a higher level of complexity to scale up.

However, [10] identified three main topologies that could be implemented when creating more complex WebRTC applications requiring multiple participants as: Peer-to-Peer Mesh topology, Multi-point Control Unit Topology, and Selective Forwarding Unit Topology

\section{B. Review of Related Works}

A lot of work has been done to improve collaboration amongst people and even students. One of which is the WebRTC based Remote collaboration system by [11] which was motivated by the desire to create a collaboration tool which had optimum performance. It was designed with HTML, CSS, JAVASCRIPT and Node.js., and also made use of Xsockets as it signals the server, and also used the mesh topology of WebRTC to implement aspect of the video calling.

The Peer-to-Peer Audio and Video Calling Application by [12] aimed at reducing students' data usage and cost in video and audio calling. It used WebRTC for audio and video communication; and WebSockets with Node.js for signaling. The system had video, audio, file-sharing and text-messaging functionalities, however only two students per session can use the system

Virtual Classroom Solution with Collaborative Context in Mathematic Learning situation by [13] was motivated by the difficulty of distance learning on practical work rooms and laboratories. It used WebRTC for it real time media communication and used ImageMagick to convert a PDF document to images to facilitate the presentation. The system had audio, video and text-messaging functionalities.

Real Time collaborative Platform for Learning and Teaching Foreign Languages by [14] was programmed in PHP along with MySQL for the database, and used WebRTC for audiovisual real time connection. It also allows students to track their progress and rate their instructors. However, some new users may have problem understanding the system.

A Web-Based Learning System Using Project-Based Learning and Imagineering aimed at encouraging self-learning and promote interaction and collaboration built with PHP and MySQL had learning management, content-management, text and deliver management systems [15]. Another reviewed system was the Web-Based Active Learning System motivated by the desire to facilitate active learning and group work in an online setting. The system was built with PHP, Node.js, WebSockets, HTML, JavaScript, WebRTC and used Google Docs. This system was successfully used to facilitate a faculty's development workshop though the video call functionality could be further extended to improve the system's aid to interaction [16].

Web Based Collaborative Learning Model for ICT Course of College Student in Bangladesh by [17] was motivated by the need to aid the students to become more efficient learner in ICT. The system runs on a window server and a web server built with Apache and it uses the MySQL as database. The system features text messaging, self-assessment and also 
provides audio, video and image explanation for better understanding

Analysis of all these works relevant to collaboration and learning established that system can be designed to facilitate group-learning and these systems must have various means of communication and collaboration like text-messaging, file sharing, video and audio calling functionalities

\section{METHODOLOGY}

The proposed system is a web-based application for studentcentered group-based learning. The development model selected for the system is the Waterfall Model. The Agile model was initially intended for the system but after the planning stage and brief requirement analysis of the system; it was discovered that the system's current requirements could be easily detected and so the Waterfall Model was quickly selected as the development model for the system due to the clarity of the System's requirements gathered from previous literatures as shown in Figure 1. The system also makes use of the WebRTC topology: SFU (Selective Forwarding Unit) for audio-visual real-time communication.

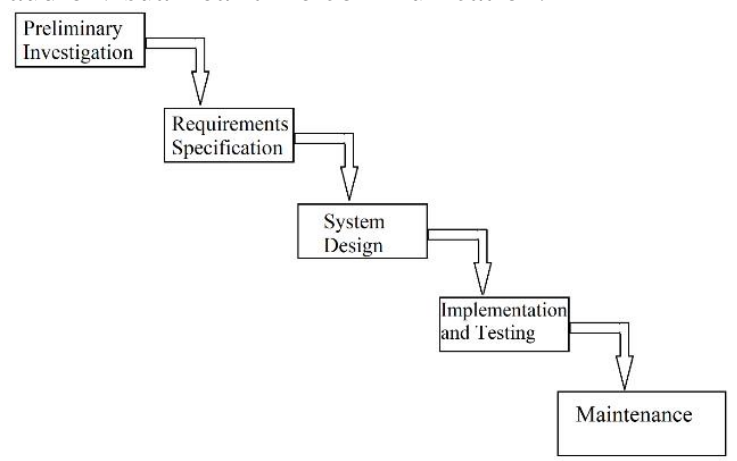

Figure 1: System Development Model

\section{A. System Requirements}

The hardware requirements are: Intel Core ${ }^{\mathrm{TM}}$ i5 and above; 4GB RAM,64-Bit Operating System; Hard Disk of 256GB and above.

The Software requirements are: Operating System: Microsoft Windows 10; Programming Language Framework: ASP.NET MVC 1.1. Main Programming Language: C\#. Front-End Languages: HTML, CSS, JavaScript, BOOTSTRAP. Database Language: Microsoft SQL with Entity Framework. IDE: Microsoft Visual Studio 2019 and above; Signaling Protocol: ASP.NET Signal R. Email API: SendGrid Email API. Background Processing API: HangFire. OpenVidu Media Server which runs on Kurento Media Server for WebRTC Connection. Docker CE for the running of the media server in command line.

\section{B. System Design}

The requirements and specifications of the system were then studied to develop the system design. The system was then divided into a number of sub-systems based on the functionalities they are intended to provide which include: The Email reminder system, The Audio and Voice communication system, the Text messaging system and the file sharing system. Due to the number of services and sub-systems incorporated in the system, an architectural pattern which is relatively easy to modify, scale, and can allow services to be added to was considered and the MVC (Model-ViewController) Architectural pattern was selected to make this possible to manage the interactions in this web-based system as shown in Figure 2



Figure 2: System Architectural Pattern Adopted for the Proposed System

\section{1) System's Subsystems and their functionalities}

The email reminder sub-system main operation is to send email reminders of any activity in a predefined email to the intended user, and ff the emails were sent immediately after creation, then this sub-system would be unnecessary as that would be the same as sending a simple email to one's self. Instead, the email-reminder system allows the user to create the email and set time limit for the reminder and then sends at the date and within the time frame it has been set for. The file sharing sub-system main function is to allow the users to send files of any type and format to their group. The main function of the text-messaging sub-system is to enable text communication among group members. This system makes use of Real-time Web Communication Protocol to enable easy communication amongst group members, in that, every message sent from one member to another doesn't need to be refreshed before it can be accessed. The Audio and Voice communication sub-system's function is to allow group audio and voice calling and communication between the group members of created groups using SFU topology of WebRTC.

\section{Overall System Design}

Taking into consideration all the different operations shown in the use-cases of each sub-system; the Use-case diagram in Figure .3 shows the operations of the users and Group admin in the system. It diagrammatically represents all the privileges a group Admin has above a regular user but also highlights the functions that users can carry out in the system 


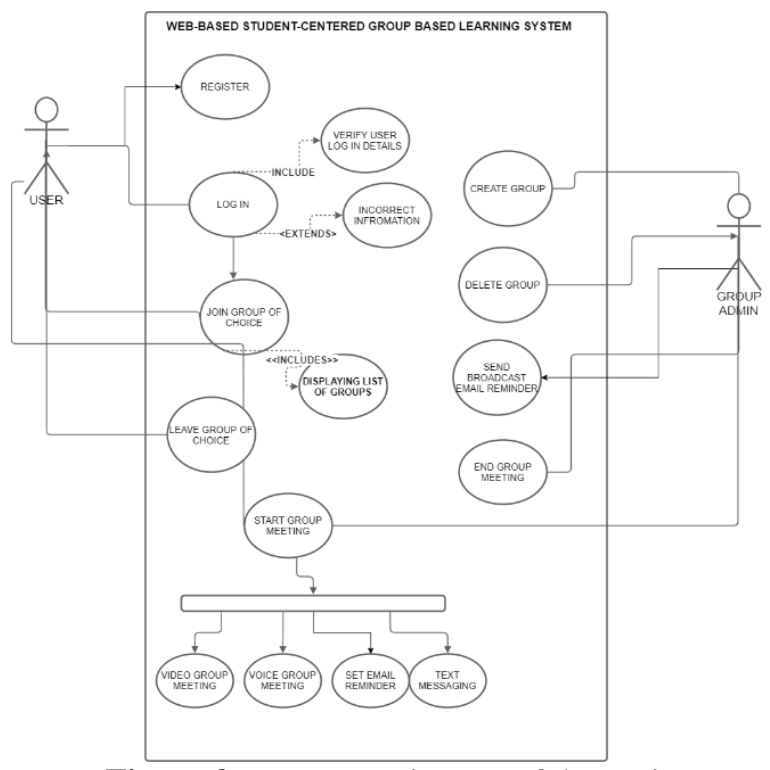

Figure 3: Use-case Diagram of the Entire system

The Figure 4 is the class diagram for the overall system. Since the system makes use of the MVC architectural pattern. This diagram structures represents the model-like structure of different aspects of the systems in terms of classes and their relationships between each other. From the Figure 4, a user can have zero or more groups, and reminders as well; a group can also have one or many reminders, blocked user relation, documents and texts, but only one video call and only one voice call.

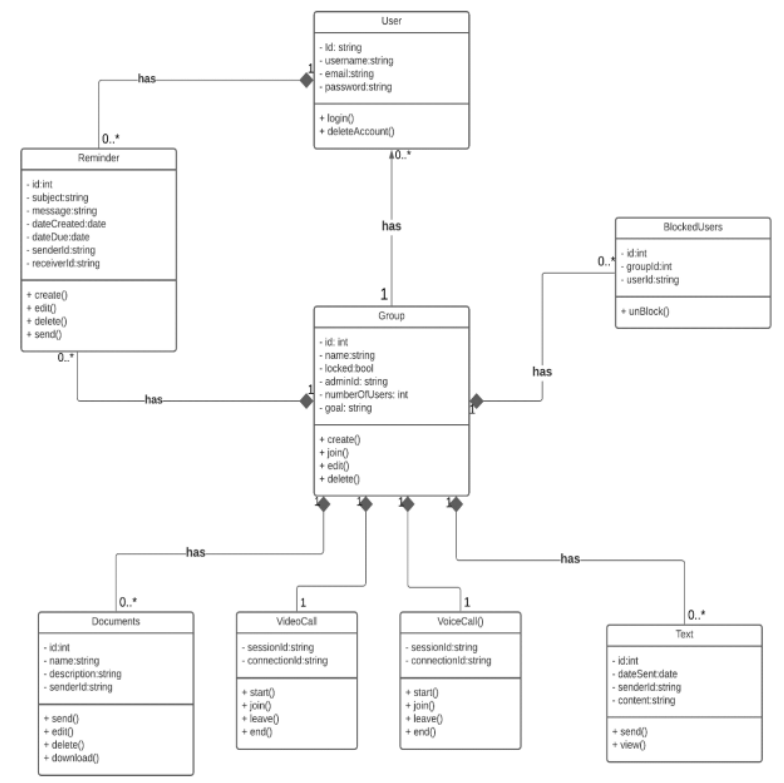

Figure 4: Class Diagram of the Entire system

Now that the system and sub-systems' designs have been thoroughly explained. The Architectural Context Diagram in
Figure 5 puts the overall system in terms of entities that interact with the software and the nature of interaction

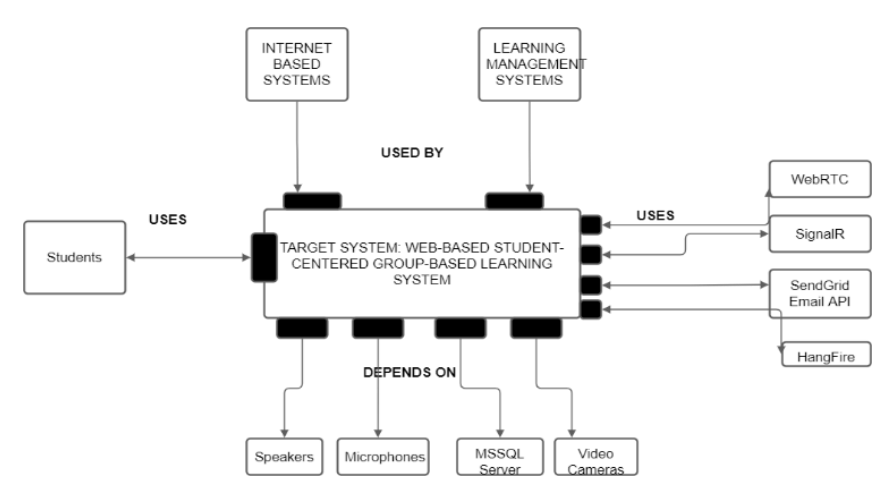

Figure 5: Architectural Context Diagram of the entire System

\section{SYSTEM IMPLEMENTATION AND RESULTS}

The system design was implemented into this system which structures and allows for effective management of studying and project groups amongst students. The design was implemented using C\# in the ASP.NET CORE MVC 3.1 frame work; HTML, CSS, BOTSTRAP, Vanilla JavaScript and other forms of JavaScript libraries were used to provide a user-friendly interface at the front end while Microsoft SQL Server served as the database management tool for backend of the system. Other tools and frameworks used for the backend of the system include OpenVidu Media Server, HangFire, SignalR and SendGrid Email API.

The system requires user registration, and email confirmation before a user can access any functionalities. The system has one interface for all classes of users; however, for users who take on the roles of group Admins. They are given administration privileges that only they can access and control within the group they have administration over. The system also consists of four sub systems which manifest as functionalities for users in the overall system, they include: An Email Reminder Sub-System, A File-Sharing Sub-System, Text-Messaging Sub-System, Video and Voice Calling SubSystem.

\section{A. The Log-In Page and Register Pages}

The Log-in page of the system presented in Figure 6 is the first page displayed to the users when the system is launched. Even if users try to access any other web page of the web application without logging into their account, they are automatically redirected to the $\log$ in page before they can access any other functionality. For users who do not have an account with the system, they are redirected to the Registration page, shown in Figure 7 from the log in page 


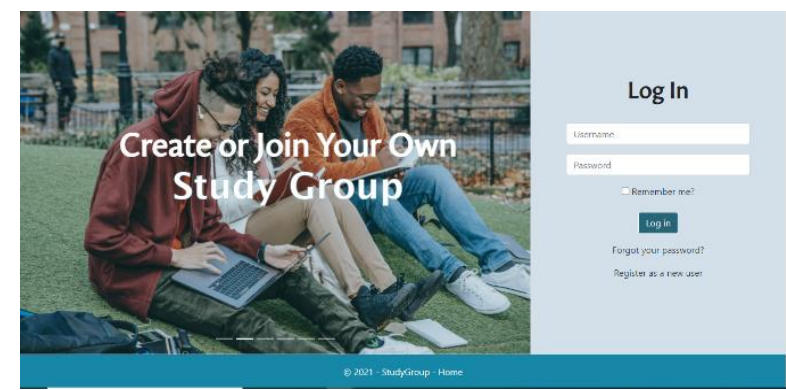

Figure 6: Login Page

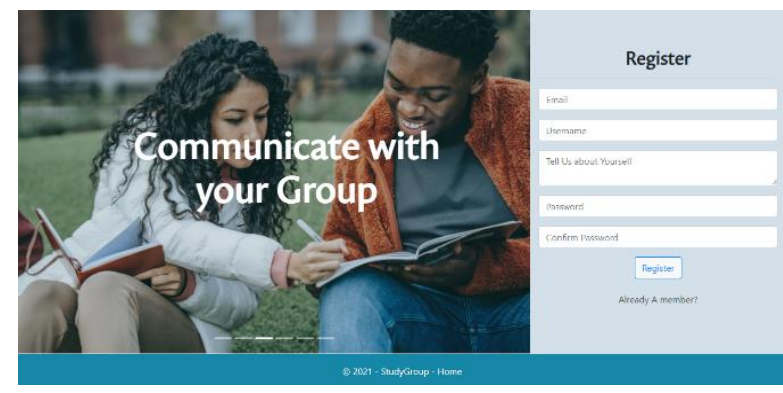

Figure 7.: Register Page

\section{B. The Home Page and Browse Group Page}

The default home page of the system, shown in Figure 8, is the user's profile page which displays their username, bio information and a button that redirects them to the manage profile page where they can make changes to their account. This page also has buttons for creating new groups. The browse group pagein figure 9 can be accessed from both the home page and the nav-bar link 'browse-groups'. It shows a list of all the groups that the user does not currently belong to and allows the user to view the group's image goal and description before joining the group. If a group is open to new users or the current user is not blocked from the group, the user will be automatically allowed into the group portal and that group will be added to the user's home page

\section{The Group Portal}

The Group's Home, shown in Figure 10 page displays the Group's image, all the group members, all the members who are blocked from the users, and a side navigation bar which allows the users to access the functions of the groups.

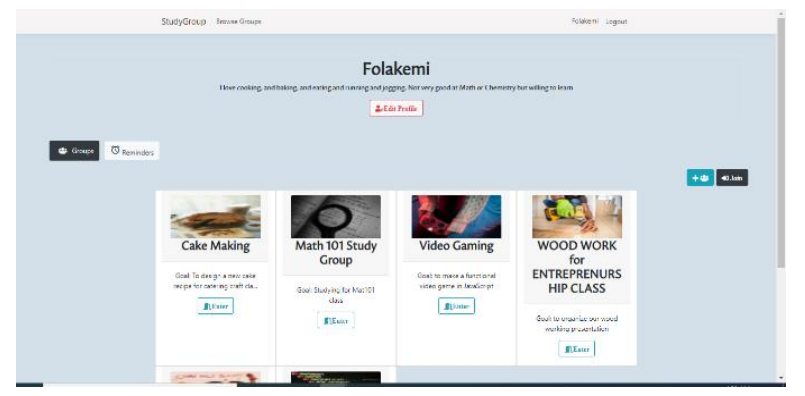

Figure 8: Home Page (Group List) For User with Groups

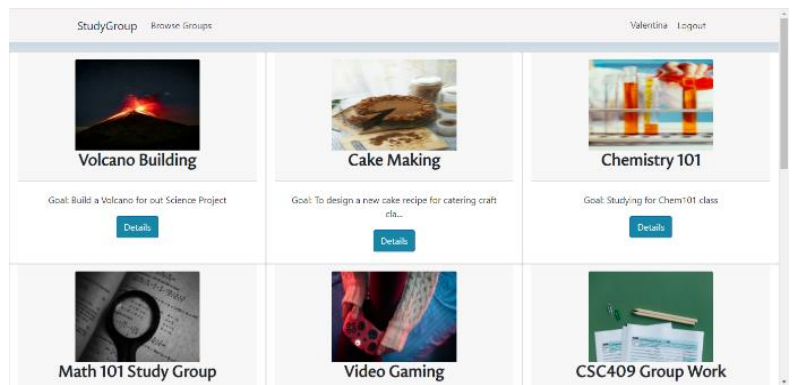

Figure 9: Browse Group Page

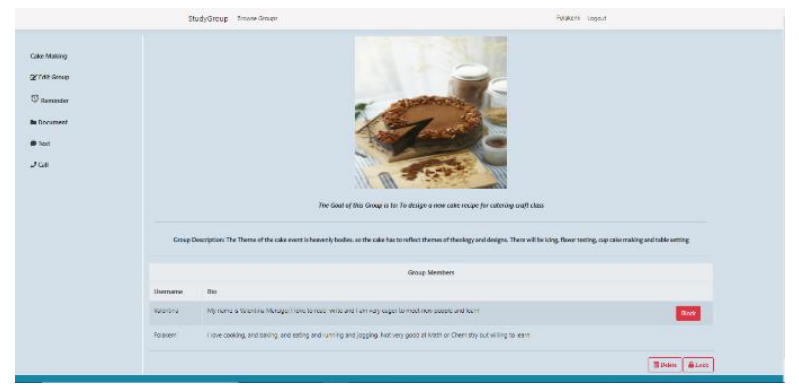

Figure 10: Group Portal (Group Admin View)

The side navigation bar has functionalities for text-messaging, group video and audio calling, sending of documents; however, the group administrator can access functionalities to edit the group and the group-reminder functionalities from the side navigation bar

From the side navigation bar in the group portal, the group administrator can access two pages for the group reminders. The Create page, shown in Figure 11 is the View All reminders page. The side navigation bar in the group portal allows all group members to access two pages for the group's documents. The Create documents page or the View All documents page in the figure 12 which shows a table of all the documents sent to the group; all group members can access the download the documents from here. However, all the group administrator or group sender can edit or delete the document sent to the group members as shown.

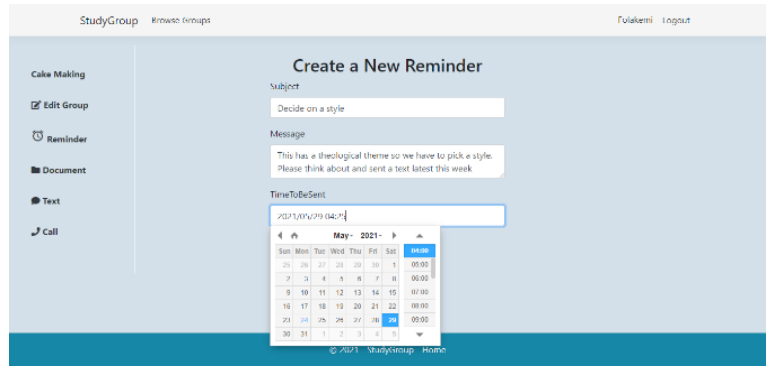

Figure 11: Create New Group Reminder 


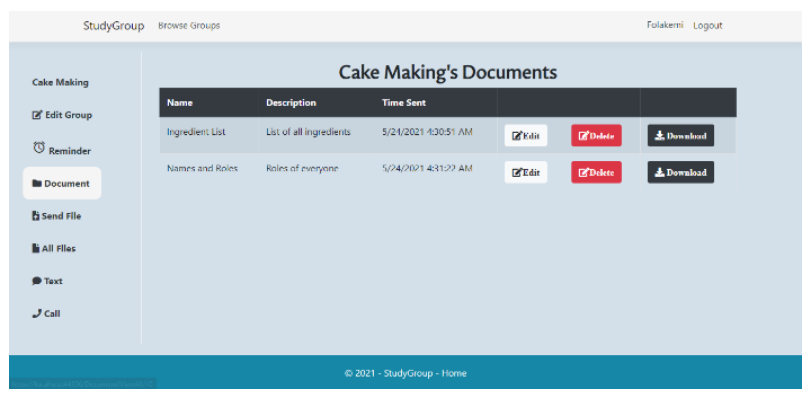

Figure 12: Group Documents Table (Group Admin View)

All group members can freely access The Text messaging page, as shown in Figure 13, from the group's side navigation bar. Once in this page, each user can freely send text messages to all other group members. The message sent from one member are automatically saved to the database and seen by all members without the need to refresh the page using realtime communication

The group's side navigation bar gives the option of either video calling or voice calling

\section{Video Calling Page}

The video calling page, as shown in Figure 14, apart from the video calling, allows the user a range of different functionalities such as Turn Off Mic, Turn Off Video, Screen Share, Leave Call and for the Administrator, The End call button terminates the session for everyone in the group and automatically redirects all users back to the group's home page

\section{Voice Calling Page}

The voice calling page, as shown in Figures 15 and 16, apart from the voice calling, allows the user a range of different functionalities such as Turn OffMic, Leave Call and for the Administrator, The End call button terminates the session for everyone in the group and automatically redirects all users back to the group's home page.

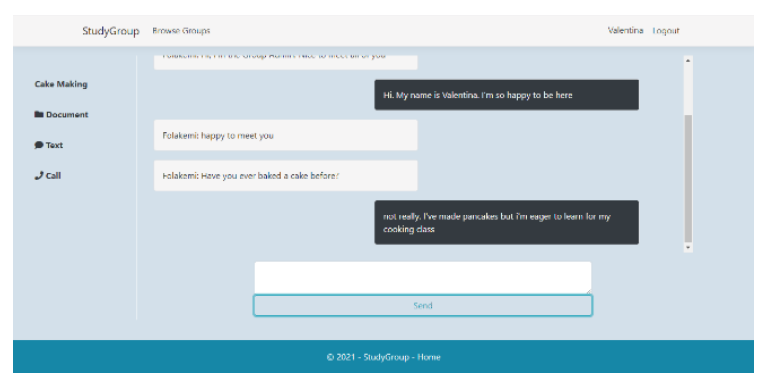

Figure 14: Group Text Page When Populated

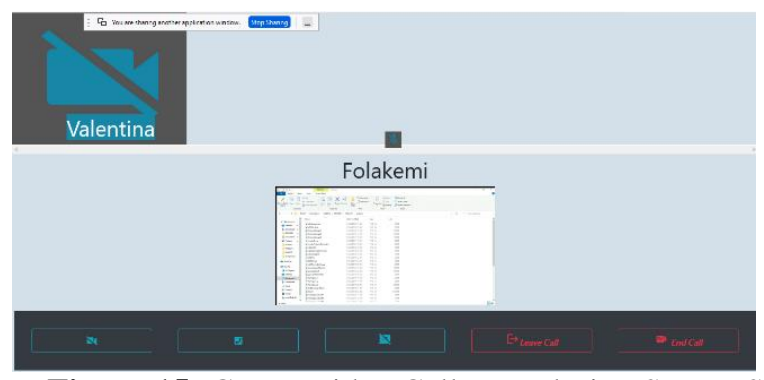

Figure 15: Group Video Call Page during Screen Sharing (The Other Camera Off)

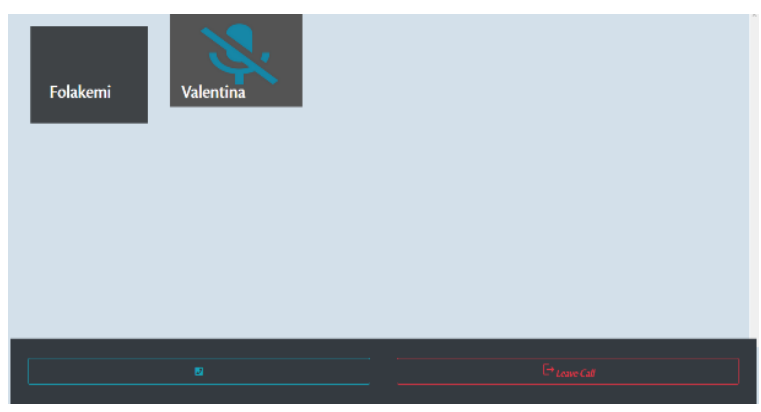

Figure 15: Group Voice Call Page with two Users (One Muted) - Member View

\section{CONCLUSION, AREAS OF FURTHER STUDY, AND RECOMMENDATION}

In this study, the issue of social loafing was critically looked at in relation to student-centered group-based learning. The design and implementation of a Student-Centered GroupBased Learning System was then performed. The system was tested and has proved to be effective in providing different forms of communication and structure to group-learning and can reduce social loafing. We therefore recommend this system for: Tertiary institutions in order to promote student-student relationship on related courses; Secondary schools, to allow students share ideas on possible group projects and presentations they have been assigned and, Libraries and reading clubs which would like members to engage and interact with the literature works better. Consequently, in the course of research, design and implementation of this work, several observations were made and as a result. We suggest that the System's functionalities be implemented to support recording of video and audio calls, in-house editing of files and the system has been implemented as a web-based application but can be further worked upon for a mobile implementation

\section{REFERENCES}

[1] Singh, Y. P., \& Agrawal, A. (2011, March). Introduction to Co-operative Learning. Indian Streams Research Journal, 1(2).

[2] Johnsohn,D.W., Johnson, R.T. \& Smith, K.A. (1991). Active Learning: Cooperation in the College Classroom. Edina, MN: Interaction. 
[3] Cheong, C. (2010). From Group-based Learning to Cooperative Learning: A Metacognitive Approach to Project-based Group Supervision. Informing Science: the International Journal of an Emerging Transdiscipline, 13.

[4] Aggarwal, P., \& O’Brien, C. L. (2008). Social Loafing on Group Projects: Structural Antecedents and Effect on Student Satisfaction. Journal of Marketing Education, 255-264.

[5] Froyd, J., \& Simpson, N. (2008). Student-Centered Learning Addressing Faculty Questions about Student centered Learning. Texas: A\&M University.

[6] Garg A. (2018). Investigating Technology Readiness and Behavioural Intention on Tablet-Based Menu Ordering Experience Among Young Adults. $7^{\text {th }}$ Asian-Euro Conference 2018.Far East University, Philipines.

[7] Doležalová, P. J. (2014). Pedagogy - the Science of Education. In J. Doležalová, J. Hábl, \& K. Janiš, Fundamental Pedagogy (pp. 12-18). Hradec Králové.

[8] Attard, A., Ioio, E. D., Geven, K., \& Santa, R. (2010). Student-Centered Learning The Notion and Its Components. In A. Attard, E. D. Ioio, K. Geven, \&

R. Santa, Student Centered Learning: An Insight Into Theory And Practice (pp. 8-15).

[9]. Foeher, B. , Sidi, L., Shabtui, A., Puzus, R. and Marozas, L. (2018). WebRTC Security Measures and Weakness, International Journal of Internet and Secured Transactions, 8(1): 78 .

[10] Dialogic: Real TimeWeb Solutions https://www.dialogic.com/2017-01-09-dialogic-receives2016-real-time-web-solutions-excellence-award
[11] Kandari, V. (2016). Implementation and Performance Optimization of WebRTC Based Remote Collaboration System: Improving Remote Collaboration. Retrieved March 31, 2021

[12] Majid, H. A., Samah, A. A., Yusuf, L., DewiNasien, \& Cheah, T. L. (2016, February). P2P Audio and Video Calling Application Using WebRTC. ARPN Journal of Engineering and Applied Sciences, 11, 1766-1770.

[13] Faye, P. M., Gueye, A. D., \& Lishou, C. (2018). 1. Virtual Classroom Solution with WebRTC in a Collaborative Context in Mathematics Learning Situation. ICST Institute for Computer Sciences, Social Informatics and Telecommunications Engineering, 66-77..

[14] Osipov, I. V., Prasikova, A. Y., \& Volinsky, A. A. (2015, June). Real Time Collaborative Platform for Learning and Teaching Foreign Languages. 1-14. Retrieved March 30, 2021, from https://www.researchgate.net/publication/271140541 _Real_Time_Collaborative_Platform_for_Learning_a nd_Teaching_Foreign_Languages

[15] Chatwattana, P., \& Nilsook, P. (2017). A Web-based Learning System using Project-based Learning and Imagineerin. International Journal of Emerging Technologies in Learning, 12, 4-22.

[16] Yoshida, L. (2019). Development of a Web-based Active Learning System and its Application. Journal of Educational Technology, 42, 81-96.Y

[17] Islam, M. T., Rahman, S. M., Galib, S. M., Uddin, K. M., \& Bashir, G. M. (2014, January). Design and Implementation of Web Based Collaborative Learning Model for ICT Course of College Student in Bangladesh. International Journal of Computer Science and Mobile Computing, 3(1), 393-400. 